\title{
PROPUESTA MICROESTRUCTURAL PARA UN DICCIONARIO DE ESPECIALIDAD LEXICOGRÁFICA
}

\section{MICROSTRUCTURAL PROPOSAL FOR A DICTIONARY OF LEXICOGRAPHICAL SPECIALTY}

\author{
Jesús CAMAChO NiÑO \\ Universidad de Jaén \\ jcnino@ujaen.es
}

Enviado: $15 / 01 / 2019$

Aceptado: 17/07/2019

\begin{abstract}
Resumen
El objetivo de esta investigación es presentar un modelo de microestructura para un diccionario de especialidad lexicográfica basado en el enfoque ofrecido por la Teoría funcional de la lexicografia. Para alcanzar la meta propuesta, en primer lugar, se propone una selección de datos lexicográficos y, segundo lugar, se presenta la estructura interna del artículo lexicográfico. Según la Teoría funcionad de la lexicografía, los diccionarios cumplen distintos tipos de funciones que dependen de varios factores: usuarios, situaciones extralexicográficas y necesidades lexicográficamente relevantes. Con esto, el diccionario planteado desarrolla dos funciones principalmente: comunicativa y cognitiva, es decir, auxilia en la producción y recepción de textos especializados en lexicografía y facilita la adquisición de conocimientos especializados en la materia. A su vez, la presencia de estas funciones determina, por un lado, los datos lexicográficos que se incluirán en la microestructura $\mathrm{y}$, por otro lado, su presentación en la interfaz lexicográfica.
\end{abstract}

\begin{abstract}
The objective of this research is to present a microstructure model for a lexicographical specialty dictionary based on the approach offered by the Function Theory of Lexicography. To reach the proposed goal, first, a selection of lexicographic data is proposed and, secondly, the internal structure of the lexicographic article is presented. According to the Function Theory of Lexicography, dictionaries fulfil different types of functions that depend on several factors: users, extra-lexicographic situations and lexicographically relevant needs. With this, the proposed dictionary develops two functions mainly: communicative and cognitive, that is, it helps in the production and reception of specialised texts in lexicography and facilitates the acquisition of specialized knowledge in the subject. In turn, the presence of these functions determines, on the one hand, the lexicographic data that will be included in the microstructure and, on the other hand, its presentation in the lexicographic interface.
\end{abstract}

Para citar este artículo / To cite this article: Camacho Niño, Jesús (2019). Propuesta microestructural para un diccionario de especialidad lexicográfica. ELUA, 33: 55-72. doi: 10.14198/2019.33.3

Enlace / Link: http://dx.doi.org/10.14198/ELUA2019.33.3 
PALABRAS CLAVE: lexicografía especializada, diccionario de especialidad, microestructura, Teoría funcional de la lexicografía, función comunicativa, función cognitiva.
KEYWORDS: specialised lexicography, specialised dictionary, microstructure, Function Theory of Lexicography communicative function, cognitive function.

\section{INTRODUCCIÓN}

Este estudio se integra en un conjunto de estudios e investigaciones (Camacho Niño, 2009; 2014; 2016a; 2016b; en prensa) cuyo objetivo es diseñar la planta de un diccionario de especialidad lexicográfica. Este elemento -la planta- constituye el sustento teórico y metodológico de cualquier diccionario, independientemente de su tipo, y en su confección, se deben tomar decisiones que atañen a aspectos tan diversos como el tipo de usuario, las fuentes, la duración del proyecto o el formato de la herramienta. Sin duda, de entre todas estas tareas, el trabajo dedicado a la microestructura cobra especial relevancia por su complejidad e importancia en cualquier tipo de dispositivo lexicográfico. Con esto, el objetivo de este estudio es presentar una selección de datos lexicográficos y su organización microestructural en un diccionario de especialidad lexicográfica en lengua española, el cual ha sido concebido a partir del marco teórico y metodológico que ofrece la Teoría funcional de la lexicografía (Bergenholtz y Tarp 1995; Tarp 2008; Tarp 2013; Fuertes-Olivera y Tarp 2014; Tarp 2015).

Para alcanzar este objetivo, el estudio se ha articulado en varias partes. En primer lugar, se ofrece una caracterización general del diccionario según los parámetros establecidos por el enfoque elegido: usuarios, situaciones, necesidades y funciones, lo cual tiene una importancia capital a la hora de determinar qué datos se seleccionan y cómo se adaptan a la microestructura. En segundo lugar, a partir de las características generales, se presentan los datos lexicográficos, diferenciados estos según su naturaleza: comunicativa o cognitiva. Finalmente, en tercer y último lugar, se incluye un ejemplo de artículo lexicográfico para la entrada lema, el cual refleja la arquitectura que tendrá la interfaz lexicográfica prototípica de las entradas del futuro Diccionario de terminología lexicográfica del español.

\section{CARACTERÍSTICAS GENERALES ${ }^{1}$}

Antes de presentar los elementos que configuran la microestructura diseñada para este futuro diccionario de terminología lexicográfica, es necesario conocer las características generales de la obra, pues son las que condicionan y justifican tanto la selección como la forma de los datos lexicográficos que se registran en el artículo.

La Teoría funcional de la lexicografía constituye un marco teórico y metodológico que permite estudiar las obras lexicográficas existentes, hacer propuestas para su mejora y aplicarlas a la creación de nuevas herramientas de consulta. Para alcanzar estas metas, este enfoque parte de un conjunto de elementos que constituyen su núcleo conceptual y terminológico: usuario - características del usuario: lengua materna, conocimientos gene-

1 Este aspecto del Diccionario de terminología lexicográfica del español se ha expuesto de una forma más exhaustiva y detallada en el estudio "Situaciones, necesidades y usuarios. Aproximación a las funciones del diccionario de especialidad lexicográfica". 
rales, conocimientos especializados, conocimientos lingüísticos, etc.-, situaciones extralexicográficas - contextos ajenos a la consulta lexicográfica en los que surgen necesidades lexicográficas: extensión de un concepto, combinaciones sintácticas habituales de una palabra, posibles traducciones de un término, entre otras- y necesidades lexicográficamente relevantes -necesidades y dudas que surgen en contextos extralexicográficos y pueden ser resueltas mediante la consulta de un diccionario-- Así, la inclusión de estos elementos en el diseño de un diccionario - sea este del tipo que sea- permite determinar el concepto central de la Teoría funcional de la lexicografía: la función lexicográfica ${ }^{2}$.

La concreción de estos aspectos en el Diccionario de terminología lexicográfica del español arroja la siguiente caracterización general

- Usuarios potenciales. Hablantes de español con un desarrollo medio y alto de sus habilidades lingüísticas. A su vez, estos son, en unos casos, especialistas en Lexicografía (expertos) y, en otros casos, estudiantes de la materia o desconocedores de ella, pero que, en un momento determinado, necesitan acercarse a algún concepto de la disciplina (semiexpertos).

- Situaciones extralexicográficas. Situaciones relacionadas con el estudio y la investigación lexicográfica (cognitivas), así como con la producción y recepción de textos especializados (comunicativas).

- Necesidades lexicográficamente relevantes de los usuarios. Datos que faciliten el estudio y la investigación lexicográfica (cognitivas), y la producción y recepción de textos especializados sobre la materia (comunicativas).

- Funciones. Satisfacer necesidades lexicográficas comunicativas y cognitivas relacionadas con un ámbito del conocimiento: la Lexicografía.

- Función genuina. Ofrecer a los usuarios - hablantes de español con un desarrollo medio y alto de sus habilidades lingüísticas y conocimientos lexicográficos- datos lexicográficos que resuelvan las dudas que potencialmente pueden surgirles en contextos comunicativos especializados.

Adicionalmente, este diccionario de especialidad lexicográfica se ha concebido inicialmente como un diccionario de Internet (Fuertes-Olivera 2012), lo cual presenta ventajas notables (difusión, desarrollo técnico, actualización de datos, etc.) frente a otros sistemas de publicación más tradicionales como el papel, si bien también exige un esfuerzo de adaptación al lenguaje y la técnica informática (Fuertes-Olivera y Tarp 2014: 195-196).

\section{MICROESTRUCTURA: INFORMACIÓN LEXICOGRÁFICA}

El elemento central del artículo lexicográfico en el Diccionario de terminología lexicográficas del español es el lema y toda la información que se incluye en la microestructura hace referencia de una forma directa o indirecta a este elemento. Los datos lexicográficos propuestos para la microestructura del Diccionario de terminología lexicográfica del español se organizan en dos categorías correspondientes a las funciones lexicográficas asociadas previamente a la herramienta diseñada (Fuertes-Olivera y Tarp 2008: 80): datos comunicativos y datos cognitivos. La existencia de estas categorías de información lexicográfica

2 La función lexicográfica se concibe como la satisfacción de las necesidades lexicográficamente relevantes de los usuarios potenciales de un diccionario en una situación extralexicográfica concreta (Tarp 2013: 465). 
responde a las funciones lexicográficas que se le han asignado previamente a la herramienta. Así, los datos lexicográficos comunicativos se refieren a las necesidades vinculadas a la función comunicativa de la herramienta y los datos cognitivos, a la función cognitiva.

\subsection{Datos comunicativos}

Los datos lexicográficos relativos a la función comunicativa del Diccionario de terminología lexicográfica del español son de naturaleza lingüística, si bien es necesario adaptarlos en su forma y contenido a las características y funciones de la herramienta de consulta en la que se integran. Por tanto, esta información lexicográfica hace referencia a las características de la unidad terminológica como signo lingüístico y para ello, se han ponderado cinco aspectos: categoría gramatical, ortografía y variantes gráficas, pronunciación, sinónimos y ejemplos. Estas categorías responden a las relaciones sintagmáticas y paradigmáticas del término y aportan información de gran valor sobre su uso, lo cual es imprescindible en una herramienta de consulta que ayude en la producción y recepción de textos (Garriga 2003: 123).

\subsubsection{Categoría gramatical}

La información sobre la categoría gramatical ha sido incluida tradicionalmente en los diccionarios de lengua (Garriga 2003: 123), si bien, en muchos diccionarios de especialidad - por ejemplo, el Diccionario de lexicografía práctica (1995) de José Martínez de Sousa o el Dictionary of Lexicography (2001) de Reinhard K. K. Hartmann y Gregory James-, no se incluye este tipo de información porque su objetivo es facilitar la adquisición de conocimientos y el aprendizaje de la disciplina a la que pertenece el término (función cognitiva) y no presentar sus características como unidad lingüística y terminológica (función comunicativa). Sin embargo, en un diccionario cuya finalidad es, entre otras, facilitar la recepción y producción de textos especializados, la categoría gramatical se convierte en un elemento de capital importancia. Para Ignacio Ahumada (2006: 4), la categoría gramatical es, junto al lema y la definición, uno de los elementos imprescindibles en la estructura mínima del artículo lexicográfico de un diccionario de lengua. Su importancia estriba en que representa "el conjunto de rasgos morfosintácticos" (Ahumada 2006: 4) del lema y, en este sentido, aporta datos relativos al comportamiento sintagmático y paradigmático de la unidad léxica lematizada (Porto Dapena 2002: 253). Con todo esto, en el Diccionario de terminología lexicográfica del español, la categoría gramatical se considera un elemento necesario, cuya presencia es obligatoria en la arquitectura del artículo lexicográfico.

En cuanto a la forma y materialización de esta información lingüística, los diccionarios no se limitan a ofrecer la categoría gramatical (verbo, sustantivo, adjetivo, etc.), también incorporan a la microestructura datos relativos a la subcategoría gramatical (transitivo, intransitivo, femenino, masculino, etc.). Y puesto que la subcategoría gramatical incluye también la categoría, la técnica lexicográfica ha optado tradicionalmente, como norma general y siguiendo el modelo lexicográfico fijado por el diccionario académico, por ofrecer únicamente la subcategoría gramatical. Habitualmente, esta información se codifica mediante abreviaturas que se colocan inmediatamente detrás del lema, si bien, actualmente, con el desarrollo de los diccionarios de Internet, no es necesario que estos datos aparezcan abreviados, pues el uso de herramientas de consulta a través de dispositivos informáticos ha 
eliminado el tradicional problema de espacio que presentaban los diccionarios impresos. En este sentido, el Diccionario de terminología lexicográfica del español, ofrece, tras el lema que encabeza el artículo, la categoría y subcategoría del término y para su codificación no se ha empleado ningún tipo de abreviatura.

\subsubsection{Ortografía y variantes gráficas}

La información ortográfica está contenida en el lema y su función es proporcionar datos que faciliten la composición de textos especializados, en este caso, sobre Lexicografía. Como afirma Cecilio Garriga (2003: 113), en numerosas ocasiones, un diccionario se consulta por la necesidad de conocer la escritura precisa, correcta o más adecuada de una palabra. En su texto, este autor se refiere a los diccionarios de lengua, si bien la idea se puede extrapolar fácilmente a los diccionarios de especialidad. Las unidades terminológicas se crean en una lengua determinada y, en algunos casos, se produce un trasvase a otros sistemas lingüísticos. En este proceso de traducción, pueden surgir distintas interpretaciones sobre la ortografía del término y el diccionario, herramienta de aprendizaje y potencial normalizador lingüístico ${ }^{3}$, debe de dar cuenta de las posibilidades ortográficas de las unidades que recoge . $^{4}$

\subsubsection{Pronunciación}

El Diccionario de terminología lexicográfica del español, como herramienta de consulta que facilita la producción de textos especializados escritos y orales incluye, necesariamente, datos sobre la pronunciación de los lemas (Bergenholtz y Tarp 1995: 202-203). Esta sería la necesidad de un usuario cuya lengua materna no es el español, pero posee una competencia comunicativa alta, y necesita saber cómo se pronuncia exactamente un término relacionado con la Lexicografía; por ejemplo, un ingeniero que informa a sus colegas de la publicación de un diccionario sobre su especialidad o un estudiante de español que esté cursando estudios relacionados con la Lexicografía y tenga que preparar una exposición. Adicionalmente, la inclusión de este tipo de información se justifica, al igual que en el caso de la ortografía, porque los términos pueden proceder de otras lenguas (Porto Dapena 2002: 192; Haensch y Omeñaca 2004: 154). La información sobre la pronunciación que aparece en el Diccionario de terminología lexicográfica del español ofrece, por un lado, la transcripción del término según los criterios del Alfabeto Fonético Internacional (AFI) y, por otro lado, un archivo de audio con la pronunciación del lema.

\subsubsection{Morfología}

Entre la información gramatical que puede ofrecer un diccionario de especialidad que cumple funciones comunicativas, se encuentra la morfología, es decir, los datos sobre la combinación de unas unidades terminológicas con otras y con otros elementos menores que la palabra. Así, el Diccionario de terminología lexicográfica del español incluye datos sobre la estructura interna de los términos. Concretamente, contempla datos relativos a la flexión

3 Esta característica cobra más importancia aún en un diccionario especializado.

4 Si un lema posee variantes ortográficas, por ejemplo, en el caso de tesoro, teasuro o thesaurus, estas se incluyen junto al lema. 
de los sustantivos, los adjetivos y verbos irregulares, si bien también se da cabida a toda la información relevante sobre la formación y estructura interna del término (Fuertes-Olivera y Tarp 2014: 212-216).

\subsubsection{Sinónimos}

Un debate lingüístico muy antiguo es el que atañe a la naturaleza de la sinonimia y las características de los sinónimos. Sin duda, este es un campo muy fructífero para la teoría y la reflexión lingüística, sin embargo, para la Lexicografía, muchas cuestiones sobre la naturaleza de los sinónimos abordadas por la Lingüística trascienden los intereses y necesidades de los usuarios de un diccionario que no sea de especialidad lingüística. Así, el Diccionario de terminología lexicográfica del español incluye, en algunos casos, los sinónimos del lema tratado, pero no con la intención de establecer un debate que aclare la cuestión lingüística de la sinonimia, sino con la de ofrecer recursos que faciliten la producción y recepción de textos especializados 5 . La inclusión de esta información "puede ser una ayuda importante para la codificación" (Garriga 2003: 114), ya que su presencia permitirá al usuario variar su estilo y lenguaje y, a la vez, hacerlo más rico y preciso (Fuertes-Olivera y Tarp 2014: 224-225; Bergenholtz 2015: 54), lo cual redundará en la calidad de su producción científica.

La información sobre la sinonimia aparece bajo un epígrafe más general: "Relaciones paradigmáticas". En esta sección del artículo lexicográfico, se sitúa el lema dentro de su sistema de referencia terminológico, lo que permite al usuario, junto a la red temática, que se expondrá más adelante, establecer relaciones y conexiones entre los términos estudiados y los conceptos lexicográficos que estos designan.

\subsubsection{Ejemplos}

La naturaleza, uso y características del ejemplo lexicográfico ha fluctuado notablemente a lo largo del tiempo. Las autoridades literarias eran el elemento central y diferenciador del primer diccionario de la Academia, pero se desecharon por cuestiones, en parte, ajenas al proceso lexicográfico. Sin embargo, actualmente, el ejemplo lexicográfico se ha convertido en un recurso que ha despertado el interés de muchos investigadores y lexicógrafos debido a las grandes posibilidades que presenta, hasta el punto de que ha sido objeto de reflexión y estudio para muchos investigadores (Jacinto García 2015).

La utilidad del ejemplo lexicográfico es innegable; José Á. Porto Dapena (2002: 194) sostiene que su objeto es doble: "de una parte ejemplificar los usos y acepciones de cada palabra y, por otra, apoyar o autorizar esos usos y acepciones". Además de estas funciones, Luis F. Lara (1992: 10) también habla de su idoneidad como vehículo para la transmisión de conocimientos, ya sean generales o especializados. Por tanto, el ejemplo lexicográfico puede desarrollar una función doble: comunicativa y cognitiva.

En el caso del Diccionario de terminología lexicográfica del español, los ejemplos ofrecen datos sobre el comportamiento lingüístico del lema tratado y para su selección,

5 Todos los términos que se incluyan como sinónimo de un lema constituirán, a su vez, una entrada en el diccionario y se podrán consultar desde los artículos en los que se registren gracias al sistema de referencias de la herramienta (medioestructura). 
se ha empleado un motor de búsqueda en Internet gratuito ${ }^{6}$. Todos ellos se han extraído de publicaciones especializadas -artículos de revistas, capítulos de libros y manuales de Lexicografía- con una antigüedad no superior a los cinco años, lo que asegura, por un lado, la actualidad del lenguaje especializado que se presenta y, por otro lado, la vigencia del concepto que se trata (Fuertes-Olivera y Tarp 2014: 218-219). Además, todos los textos especializados que se han empleado como ejemplo están disponibles para su consulta en Internet y se puede acceder a ellos desde la referencia bibliográfica que aparece al final de la cita.

\subsection{Datos cognitivos}

El Diccionario de terminología lexicográfica del español ha sido diseñado como una herramienta que ayuda a sus usuarios, expertos y semiexpertos en Lexicografía, a adquirir y ampliar sus conocimientos sobre la materia en la que trabajan, estudian o investigan. Por ello, el diccionario debe, por un lado, incluir la mayor cantidad posible de datos lexicográficos con función cognitiva relevantes y necesarios para sus usuarios $\mathrm{y}$, por otro lado, optimizar la selección de estos y su presentación en la interfaz lexicográfica, ya que la herramienta debe proporcionar caminos y rutas de acceso a la información específicas según el perfil de usuario previsto sin que ello comprometa su funcionalidad. Para conseguirlo, se han establecido cuatro niveles de datos cognitivos: clasificación temática, definición, información especializada y red temática. Esta distribución por niveles ayuda a jerarquizar la información cognitiva, ya que permite situar el término dentro de la disciplina (clasificación temática), caracterizarlo (definición lexicográfica), analizarlo (información especializada) y, finalmente, relacionarlo con sus conceptos adyacentes (red temática).

\subsubsection{Clasificación temática}

Los términos empleados en una ciencia concreta como la Lexicografía dan forma a un conjunto de conceptos que establecen relaciones internas hasta formar una red autónoma. Para un usuario que se acerque al diccionario con la necesidad de saber qué es la Lexicografía y cómo se articula internamente, será de gran utilidad conocer a qué parte de la disciplina se puede adscribir el término consultado. Por tanto, la inclusión de esta clasificación de los términos lematizados refuerza la función cognitiva del Diccionario de terminología lexicográfica del español.

El diccionario presenta una estructura muy compleja en la que los distintos conceptos se interrelacionan provocando que su clasificación sea una tarea difícil en la que fácilmente se puede perder la objetividad. Por ello, la propuesta de clasificación conceptual se completa con los datos que se registran en la red temática, lo que ofrecerá una visión más completa y precisa de la estructura interna de la disciplina.

En cuanto a la clasificación, se ha partido de una formulación hecha en investigaciones anteriores (Camacho Niño, 2015: 93-95 y 2016a: 216), a la cual se han añadido varios elementos:

6 El motor de búsqueda usado ha sido Google, pues es el más potente y el que ofrecer mayor cantidad de datos. 


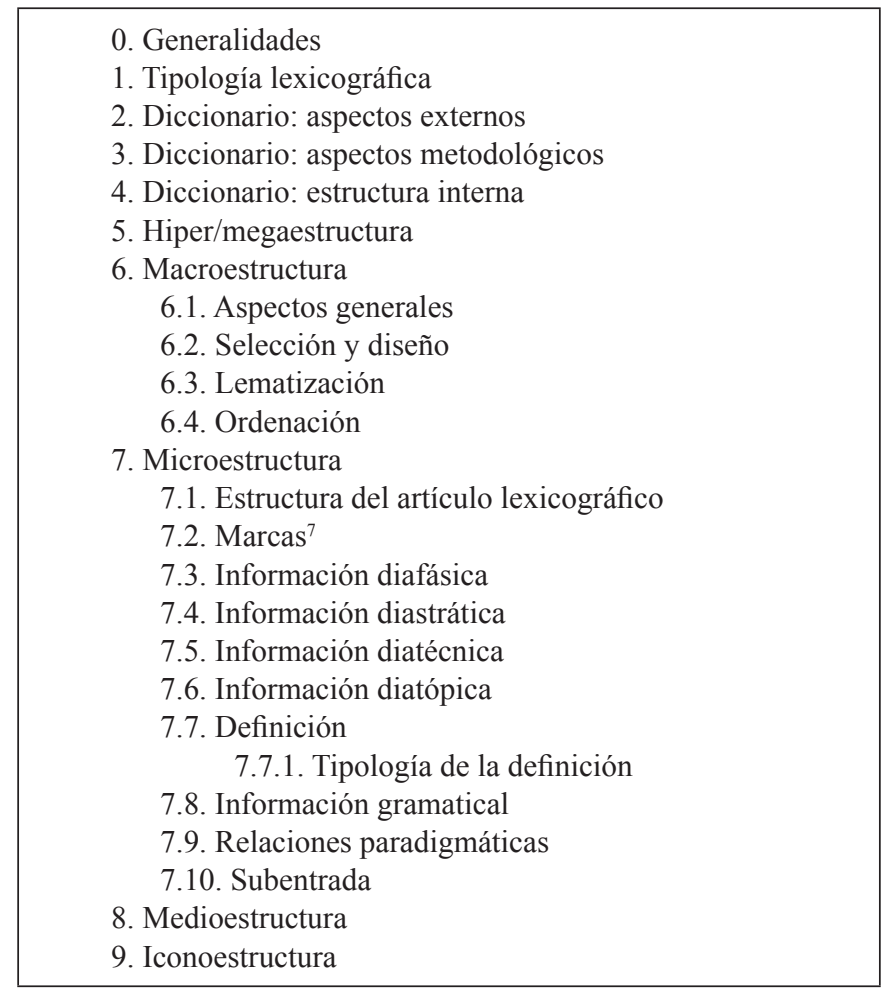

Cuadro I. Propuesta de clasificación conceptual

La metodología aplicada para la creación de esta propuesta de clasificación interna de la Lexicografía se basa en la observación de la terminología lexicográfica registrada en unas fuentes muy concretas ${ }^{8}$, las cuales no serán las únicas que se manejarán en el diseño y confección del lemario definitivo del Diccionario de terminología lexicográfica del español. Por tanto, esta clasificación se someterá a distintas reformulaciones a lo largo del proceso de producción de la herramienta.

\subsubsection{Definición lexicográfica}

La definición es el punto central de muchos diccionarios, especialmente monolingües definitorios, y definir es una de las acciones más complejas y comprometidas de cuantas afronta

7 Se ha establecido una diferencia entre marca e información diasistemática, porque el concepto de marca y marcación es más amplio y, por tanto, no es adecuado circunscribirlo únicamente a la descripción de la variación diasistemática o la información gramatical. Por ejemplo, hay ciertas marcas que activan la medioestructura del diccionario, las cuales no tienen nada que ver con los aspectos anteriores. Por otra parte, la información diasistemática y gramatical tampoco se codifica siempre mediante marcas lexicográficas, por ejemplo, cuando aparece integrada en la definición a través del entorno (Porto Dapena 2014)

8 Los dos artículos a los que se hace referencia se centran en el estudio de la terminología lexicográfica incluida en los diccionarios generales del español. 
un lexicógrafo. Estos textos, al igual que el resto de la información de una herramienta como el diccionario, presentan un alto grado de codificación y normalización, lo que, además de dificultar su elaboración, requiere un conocimiento profundo de la técnica lexicográfica y mucha práctica. La definición presenta una forma y función muy variable según el tipo de diccionario, es decir, según el usuario prototípico y las distintas funciones que se le hayan asignado.

Tradicionalmente, se ha considerado que los diccionarios de especialidad empleaban definiciones enciclopédicas (Bosque 1982: 111-116; Porto Dapena 2002: 277-284; Medina Guerra 2003: 143; Porto Dapena 2014: 45-54), cuyo fin no es delimitar la extensión semántica de la unidad definida con respecto al resto de unidades léxicas circundantes dentro del sistema, sino describir, de forma más o menos exhaustiva y mediante el uso de la palabra, las características del referente. Sin embargo, tal y como expone y demuestra José Á. Porto Dapena (2014: 56-59), esta definición no es la que realmente se ha aplicado, ni la más adecuada para este léxico.

Una unidad terminológica forma parte del sistema lingüístico, pero de una forma especial, ya que constituye "el soporte de la especialidad, puesto que designa el objeto y lo identifica como propio de una actividad determinada" (Contreras Izquierdo 2008: 42). Por tanto, un término es una palabra que designa "una clase o prototipo de objetos mentalmente establecidos gracias a un proceso de abstracción -es decir, a una conceptualización-" (Porto Dapena 2014: 53). Con esto, la definición que mejor se ajusta a las necesidades definicionales de estas unidades léxicas es la lingüistica (conceptual) designativa o referencial, ya que permite relacionar el plano lingüístico y el conceptual (Porto Dapena 2014: 55). Este tipo de definición permite al usuario conocer la extensión conceptual de los términos y distinguir los elementos diferenciadores de cada uno de los referentes a los que designan estos términos.

Además de la tipología, es necesario contemplar otros aspectos en el diseño de las definiciones empleadas en el Diccionario de terminología lexicográfica del español. Su extensión no está limitada por ningún tipo de restricción espacial, pero deben ser claras, precisas y no incluir ningún elemento redundante o innecesario. Para ello, se han seguido cinco principios (Agerbo 2018: 62-63):

- Relevancia. Todos los datos que se incluyan en la definición deben ser relevantes para el usuario.

- Estructuración. Los datos siempre deben seleccionarse según las funciones del diccionario.

- Comprensible. El lenguaje empleado en la redacción debe ser claro y comprensible para el tipo de usuario seleccionado.

- Corrección. Todos los datos que se incluyan en la definición deben ser correctos y proceder de fuentes fiables y contrastables.

- Autonomía. Los datos incluidos en la definición deben ser suficientes de forma que el usuario no tenga que hacer búsquedas adicionales innecesarias.

En lo que respecta a su construcción y redacción, las definiciones deben ser, ante todo, suficientes, pues "los usuarios que consultan un diccionario para aumentar sus conocimientos sobre algún tópico necesitan sobre todo definiciones [...] de las cuales puedan extraer informaciones correctas y actualizadas" (Fuertes-Olivera y Tarp 2008: 81). Esto supone un análisis exhaustivo de los elementos esenciales de cada concepto, lo que permite obtener textos definicionales adecuados a las funciones atribuidas al diccionario y a las necesidades de sus usuarios. Para seleccionar los elementos esenciales del concepto que deben aparecer 
en la definición, se ha partido de la propuesta metodológica presentada Heidi Agerbo (2018: 70-74), la cual se basa en la selección y combinación de un conjunto de parámetros y fuentes (empirical basis). Este método determina las fuentes más adecuadas para el diccionario que se está elaborando, a partir de la conjunción de dos elementos: función genuina (usuarios y situaciones) y tipo de dato lexicográfico (significado, gramática, colocaciones, etc.). En el caso del Diccionario de terminología lexicográfica del español, las fuentes definicionales tienen la siguiente configuración:

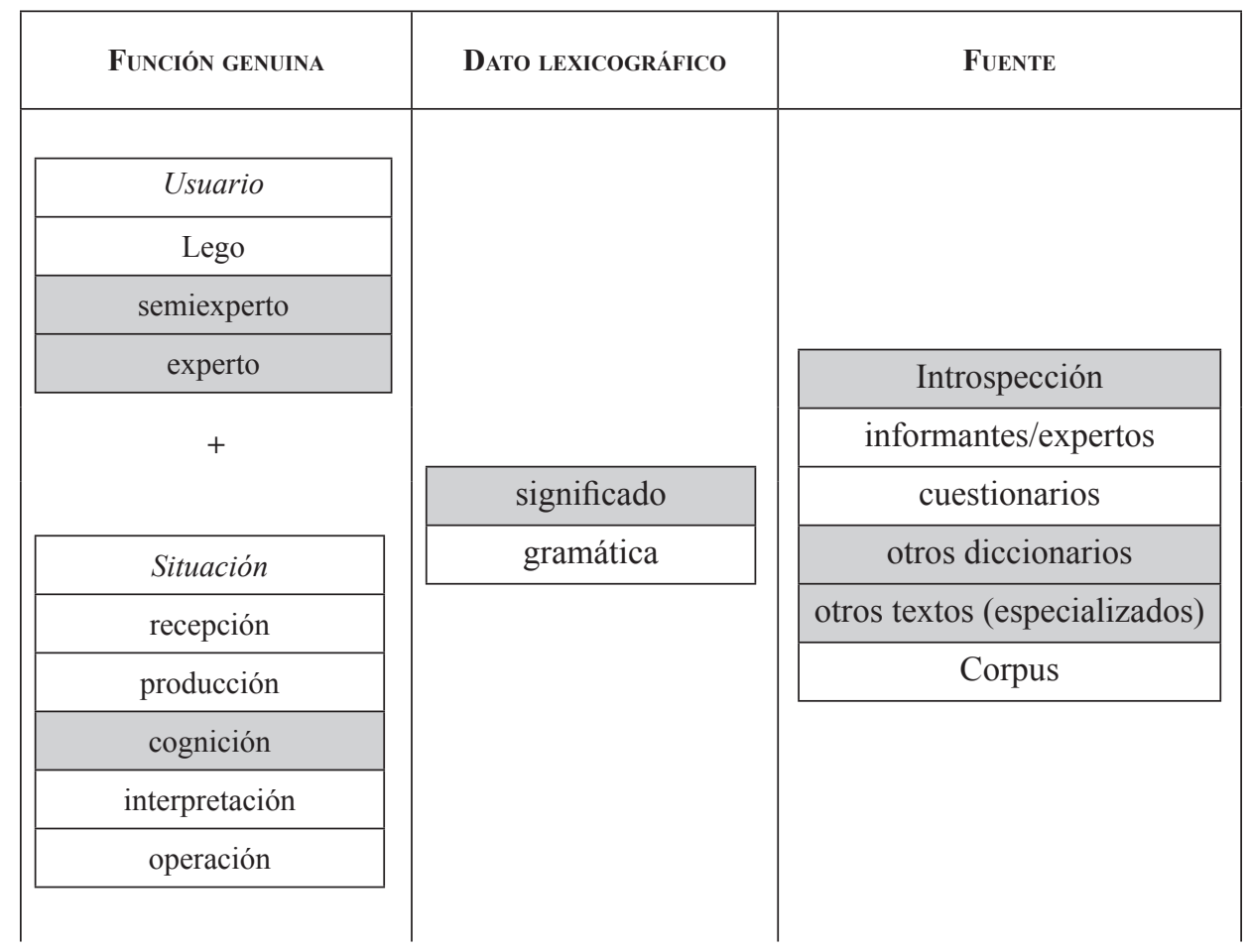

Cuadro II. Configuración de las fuentes definicionales

Así, según lo expuesto en el cuadro anterior, se emplean tres fuentes: introspección (reflexión basada en los conocimientos que el redactor de la definición tiene sobre la materia), otros diccionarios (consulta del término en otros diccionarios de especialidad lexicográfica) y otros textos (consulta de estudios e investigaciones sobre Lexicografía: manuales, monografías y artículos).

\subsubsection{Información especializada}

Este nivel de información cognitiva se encuentra estructurado, a su vez, en tres secciones, que representan distintos grados de especialización de los datos: general, especializado y ultraespecializado. El objetivo de esta segmentación es facilitar la selección y jerarquizar 
la información que necesita el usuario en su consulta. Las dos primeras secciones son especialmente interesantes para los usuarios semiexpertos, mientras que la tercera lo es para los expertos. Las fuentes empleadas para la confección de estos datos han sido de dos tipos: especializadas (investigaciones y estudios sobre Lexicografía) y lexicográficas (diccionarios generales y de especialidad).

\subsubsection{Sección general}

En este primer nivel, se presentan datos lexicográficos extraídos de fuentes generales de consulta en Internet con el fin de que el usuario obtenga una caracterización básica del concepto realizada desde una perspectiva no especializada. Es un nivel muy básico de conocimiento especializado, pero totalmente necesario en aquellos usuarios que se encuentren por primera vez ante la necesidad de conocer o abordar un concepto lexicográfico. Las fuentes que aparecen en esta sección son herramientas de consulta generales y su selección responde a la forma en la que actualmente se accede a la información, por eso todas ellas están en Internet y su acceso es gratuito. Estas son Google (diccionario integrado), Wikipedia/Wikcionario, Diccionario de la lengua española (2018 [2014]), CLAVE. Diccionario de uso del español actual (2012) y Diccionario Salamanca de la lengua española (1996).

\subsubsection{Sección especializada}

Los datos que se recogen en el segundo nivel permiten hacer una caracterización del término desde un enfoque especializado, lo cual es de gran utilidad para aquellos usuarios que poseen un conocimiento básico de la Lexicografía, pero tienen necesidad de ampliarlo (usuarios semiexpertos). Así, en este apartado, aparece, en primer lugar, una nota de carácter historiográfico sobre la recepción del término en la lexicografía general del español ${ }^{9}$, en segundo lugar, un resumen de la información que registra el Diccionario de lexicografía práctica (1995) de José Martínez de Sousa ${ }^{10}$ y, en tercer lugar, una selección de referencias bibliográficas fundamentales para la disciplina. La lengua predominante en estas será el español, si bien también se incluyen textos en otras lenguas, especialmente en inglés, cuando se considera necesario. Asimismo, para su confección, se han empleado, principalmente, cuatro herramientas ${ }^{11}$ : la Bibliografía temática de la lexicografía (2003) de Félix Córdoba Rodríguez $^{12}$, los tres volúmenes del Diccionario Bibliográfico de la Metalexicografía del Español (2006, 2009 y 2014) de Ignacio Ahumada (Dir./Ed.) y la Euralex Bibliography of Lexicography ${ }^{13}$.

9 Los datos correspondientes a esta parte han sido extraídos del trabajo de Tesis doctoral Teoría de la lexicografía en diccionarios monolingües del español (Origenes-siglo XXI) presentado en 2014.

10 La inclusión de esta información en el diccionario es provisional, ya que es una obra sujeta a derechos de autor. Por tanto, será necesario las vías editoriales que permitan el aprovechamiento de esta información.

11 La elección de estas cuatro herramientas se justifica por dos razones. En primer lugar y principalmente, porque son las recopilaciones bibliográficas sobre lexicografía más actuales, extensas y exhaustivas. Además de las referencias, estas obras presentan una organización temática de estas, lo cual facilita la clasificación y selección de las referencias bibliográficas que se han de incluir en la microestructura del Diccionario de terminología lexicográfica del español. Y en segundo lugar, se recomiendan en la página web de la Asociación Española de Estudios Lexicográficos.

12 Disponible en línea: Bibliografia temática de la lexicografia.

13 Disponible en línea: European Bibliography of Lexicography. 


\subsubsection{Sección ultraespecializada}

Este último nivel representa el grado más alto de especialización de los datos cognitivos y en él se presentan distintas investigaciones y estudios sobre aspectos concretos, tanto teóricos como prácticos, del término que encabeza el artículo. Con esta sección, se busca ofrecer una información lo más específica posible sobre el lema, lo cual es especialmente útil para los usuarios expertos, por ejemplo, si necesitan conocer cuáles son los aspectos más trabajados de un concepto lexicográfico o sus investigaciones más recientes. Por ello, las referencias bibliográficas se han seleccionado atendiendo, principalmente, a su fecha de publicación, de forma que se garantice que la información y los datos están actualizados ${ }^{14}$.

En esta sección, se presenta, en primer lugar, una breve nota sobre los aspectos más tratados en la bibliografía sobre ese concepto $y$, en segundo lugar, las referencias propiamente dichas.

\subsubsection{Red temática}

La red temática es el cuarto nivel de información cognitiva y se inspira en la sección Red de información terminológica del Wörterbuch zur Lexikographie und Wörterbuchforschung. Dictionary of Lexicography and Dictionary Research (2010, 2017) de Herbert E. Wiegand, Michael Beißwenger, Rufus H. Gouws, Matthias Kammaner, Angelika Storrer y Werner Wolski (Eds.) (2010, 2017). Su función principal es completar los datos que aparecen en la clasificación temática. A partir de una imagen esquemática y jerarquizada, se presentan los términos que establecen relaciones conceptuales con el lema que encabeza el artículo lexicográfico. Este elemento fortalece la función cognitiva de la obra, ya que ofrece al usuario una muestra de la estructura y relaciones internas que contraen entre sí los conceptos de la disciplina. Además, estos datos pueden emplearse con fines comunicativos, ya que la red temática también recoge los sinónimos que se incluyen en la parte comunicativa de la microestructura. Por ello, se han añadido elementos diferenciales ${ }^{15}$ con los que el usuario pueda identificar de una forma rápida y económica, en costes de esfuerzo, cuáles son los elementos del mapa que también se incluyen como sinónimos del lema.

\section{ESTRUCTURA DEL ARTÍCULO LEXICOGRÁFICO}

Además de seleccionar y justificar la información que debe aparecer en la microestructura, también es necesario decidir qué estructura y disposición tendrá esta información a lo largo de la entrada lexicográfica (Porto Dapena 2002: 182; Atkins 2008: 35-48). Es decir, configurar la arquitectura del artículo lexicográfico, la cual estará determinada, como en el caso de los datos lexicográficos, por la función o funciones de la herramienta lexicográfica diseñada (Fuertes-Olivera y Tarp 2014: 233).

Existen muchas posibilidades de ordenación de los datos incluidos en la microestructura

14 El Diccionario de terminología lexicográfica del español, al estar concebido como un diccionario de Internet, puede actualizarse de una forma rápida, sencilla y sin un coste económico notable para el proyecto.

15 Los sinónimos aparecen a la izquierda del lema con una paleta de colores diferente. 
de una herramienta de consulta, lo cual ha dado lugar a una tipología muy amplia (Wiegand 2013: 149-214). En el caso del Diccionario de terminología lexicográfica del español, la estructura prototípica del artículo lexicográfico se compone de tres subestructuras parciales a lo largo de las cuales se distribuyen los datos lexicográficos: cabecera, información comunicativa e información cognitiva. La existencia y la identificación de estas estructuras menores dentro del artículo lexicográfico agiliza y optimiza el acceso a los datos y, por tanto, el proceso de consulta, ya que permite al usuario acudir directamente al dato que precisa en cada momento (Gouws 2018: 52-55).

En la cabecera, se combinan datos comunicativos y cognitivos. Así, aparece, en primer lugar, el lema, el cual incluye la información ortográfica y constituye el núcleo de la unidad de análisis (Porto Dapena 2002: 183), y bajo este, la transcripción fonológica y un archivo de audio con la pronunciación. En una posición inmediatamente por debajo de los datos sobre la pronunciación, se sitúa la categoría y subcategoría gramatical y, a continuación, en un nivel inferior, la clasificación temática. La segunda subestructura parcial -datos comunicativos - registra los siguientes elementos: morfología, relaciones paradigmáticas (sinónimos), y ejemplos, en los cuales aparece resaltado el término que se analiza en el artículo y permiten la consulta del texto completo a través de un hipervínculo insertado en la referencia bibliográfica. Finalmente, la tercera subestructura -datos cognitivos-incluye las siguientes secciones: definición, información especializada (general, especializada y ultraespecializada) y red temática.

Para ilustrar esta descripción, a continuación, se presenta el modelo de artículo lexicográfico para el término lema:

\author{
Lema \\ /'lema/ \\ [archivo de audio: pronunciación] \\ sustantivo masculino \\ 6. Macroestructura \\ 6.3. Lematización
}

Morfología

INFORMACIÓN COMUNICATIVA (lingüística)

Lema es una unidad lingüística simple con una flexión de número regular:

Paradigma flexivo: lema - lemas

Relaciones paradigmáticas

Sinónimos: entrada

\title{
Ejemplos
}

«Este pues será también el recorrido de mi propuesta para revisar la lexicografía del español actual a la luz del lema andamio y, desde esta perspectiva, entrever algunas propuestas que podríamos hacerle a esta disciplina de hacer diccionarios de la lengua española y recordar las necesidades y las posibilidades que hay en la lexicografía actual del español global» (Battaner Arias, 2014: s.p.).

«El perjuicio para esta rama de la lexicografía es visible cuando consultamos la mayoría de los diccionarios especializados existentes hasta la fecha: normalmente solo tienen un lema 
y uno o varios equivalentes, o un lema y una definición más o menos compleja» (FuertesOlivera y Tarp, 2015: 228).

\section{Definición}

INFORMACIÓN COGNITIVA (especializada)

Elemento, generalmente de naturaleza lingüística, que encabeza los artículos lexicográficos de una herramienta de consulta y al que se dirigen todos los datos que contienen estos. Es producto del proceso de lematización y constituye un punto de contacto entre la macroestructura y la microestructura, porque, además de encabezar el artículo lexicográfico, es la ruta de acceso a la entrada lexicográfica y permite su localización en el conjunto del lemario. Incluye información ortográfica y, en la lexicografía española, por sus características gráficas, también sobre la pronunciación.

\section{Información especializada}

Sección general

- $\quad$ Google (diccionario integrado)

- $\quad$ Wikcionario

- $\quad$ Diccionario de la lengua española (2018 [2014])

- $\quad$ CLAVE. Diccionario de uso del español (2012)

- $\quad$ Diccionario Salamanca de la lengua española (1996)

Sección especializada

\section{Recepción en la lexicografía general}

La primera vez que se registra este término en la lexicografía general del español es en el Diccionario de uso del español (1966) de María Moliner, el cual marca la acepción como perteneciente a la Lingüística (Ling.) y ofrece la siguiente definición: "Cada una de las palabras que se definen en un diccionario o enciclopedia" (DUE, 1966: s.v. lema). El Diccionario general ilustrado de la lengua española (1987) de Manuel Alvar Ezquerra (Director de la nueva redacción) marca el término como propio del ámbito filológico y ofrece una definición más especializada: "Voz que se emplea como entrada de un artículo lexicográfico, y que representa todas las formas paradigmáticas que pueda tener" (DGILE, 1987: s.v. lema). Algunos diccionarios, como LEMA. Diccionario de la lengua española (2001) de Paz Battaner (Dir.), optan por no incluir ningún tipo de marcación diatécnica y otros, como el Diccionario del español de México (2010) de Luis F. Lara (Dir.) o CLAVE. Diccionario de uso del español actual (2012 [1996]) prefieren acotar aún más la delimitación e incluyen en la definición un entorno pragmático de especialidad (Porto Dapena, 2014: 235-263): "En lexicografia, conjunto constituido por la entrada y su marca gramatical en un diccionario" (DEM, 2010: s.v. lema) y "En un diccionario o enciclopedia, término que encabeza cada artículo y que es lo que se define" (CLAVE, 2012 [1996]: s.v. lema). Finalmente, la Academia recoge por primera vez este término en la vigésima segunda edición de su diccionario (2001) marcándolo como perteneciente a la Lingüística y remitiendo al artículo lexicográfico entrada. En la edición actual (2018 [2014]), se mantiene la marcación diatécnica y se incluye una definición: "Palabra que encabeza un artículo de un diccionario o de una enciclopedia" (DLE, 2018 [2014]: s.v. lema).

\section{Recepción en la lexicografía de especialidad}

La información que registra sobre este término el Diccionario de lexicografía práctica (1995) de José Martínez de Sousa es muy breve y se limita a la etimología y a una remisión al artículo lexicográfico entrada: 
Lema. (del lat. lemme, y este del gr. lêmma). entrada (DLP, 1995: s.v. lema).

\section{Referencias bibliográficas:}

- Bajo Pérez, E. (2000). «Lema y lematización», en Los diccionarios. Introducción a la lexicografía española (22), Gijón: TREA.

- Castillo Carballo, M. ${ }^{a}$ A. (2003). «La macroestructura del diccionario», en A. M. ${ }^{a}$ Medina Guerra (Coord.), Lexicografía española (79-101), Barcelona: Ariel.

- Haensch, G. y Omeñaca, C. (2004). «Breve introducción a la lexicografía», en Los diccionarios del español en el siglo XXI (19-50), Salamanca: Ediciones de la Universidad de Salamanca.

- Porto Dapena, J. Á. (2002). «La macroestructura del diccionario: las entradas», en $\mathrm{Ma}$ nual de técnica lexicográfica (135-181), Madrid: Arco Libros.

- Rodríguez Barcia, S. (2016). «La macroestructura», en Introducción a la lexicografia (197-211), Madrid: Síntesis.

Sección ultraespecializada

Los estudios e investigaciones sobre el término lema más abundantes en la bibliografía está relacionados con aspectos vinculados a la teoría y la práctica lexicográfica: lematización, ordenación de los lemas, tipos de lemas y entradas y lemas homónimos y polisémicos.

Lematización:

- Bergenholtz, H. y Gouws, R. H. (2017). «The access Process in Dictionaries for Fixed Expressions», en Lexicographica (23), 237-260.

- Fenlon, J., Cormier, K. y Schembri, A. (2015). «La lematización de voces homónimas en los diccionarios actuales del español», en International Journal of Lexicography (28/2), 169206.

- Fuertes-Olivera, P. A. y Tarp, S. (2014). «Lemma Selection», en Theory and Practice of Specialised Dictionaries (200-205), Berlín, Boston: De Gruyter.

- Prinsloo, D. (2009). «Current Lexicography Practice in Bantu with Specific Reference to the Oxford Northern Sotho School Dictionary», en International Journal of Lexicography (22/2), 151178.

Ordenación de los lemas:

- Ahumada Lara, I. (2004). El arte de ordenar las palabras y los conocimientos, Jaén: Servicio de Publicaciones de la Universidad de Jaén.

- Heid, U., Prinsloo, D. y Bothma, T. (2012). «Dictionary and corpus data in a common portal: state of the art and requirements for the future», en Lexicographica (28/1), 269-292.

- Tarp, S., Fisker, K. y Sepstrup, P. (2017). «L2 Writing Assistants and Context-Aware Dictionaries: New Challenges to Lexicography», en Lexikos (27), 494-521.

- Tipos de lemas y entradas:

- Bergenholtz, H. y Gouws, R. H. (2017). «Polyseme Selection, Lemma Selection and Article Selection», en Lexikos (27), 107-131.

- Castillo Carballo, M. ${ }^{a}$ A. (2005). «El lema. Tipos de entradas», en M. Alvar Ezquerra (Coord.) Lexicografia. Liceus. Portal de Humanidades (1-19), Madrid: Liceus, Servicios de Gestión y Comunicación.

- Gouws, R. H. (2007). «The Selection, Presentation and Treatment of Cultural Phrases in a Multicultural Dictionary», en Lexicographica (22), 24-36.

- Wójtowicz, B. (2017). «Revisiting Lemma Lists in Swahili Dictionaries», en Lexikos (27), 561-577.

- Xue, M y Tarp, S. (2018). «Towards Chinese Learner's Dictionaries for Foreigners Living in China: Some Problems Related to Lemma Selection», en Lexikos (28), 384-404. 
Lemas homónimos y polisémicos:

- Beyer, H. L. (2018). «On the Proposals to Abolish Polysemy and Homonymy in Lexicography», en Lexikos (28), 1-31.

- Clavería Nadal, G. y Palanas (2001). «La homonimia en la lexicografía española», en Nueva revista de Filología Española (XLIX/2), 281-306.

- Perdiguero Villarreal, H. (2000-2001). «La lematización de voces homónimas en los diccionarios actuales del español», en Revista de Lexicografia (VII), 111124.

- Stebbins, T. (2004). «Polysemy, Homonymy and Sense Modulation in Sm'algyax», International Journal of Lexicography (17/1), 1-32

- Tarp, S. (2001). «Lexicography and the linguistic concepts of homonymy and polysemy», en Lexicographica (17), 22-39.

- Tarp, S. (2009). «Homonymy and Polysemy in a Lexicographic Perspective», en Zeitschrift für Anglistik und Amerikanistik (57/3), 289-305.

Red temática

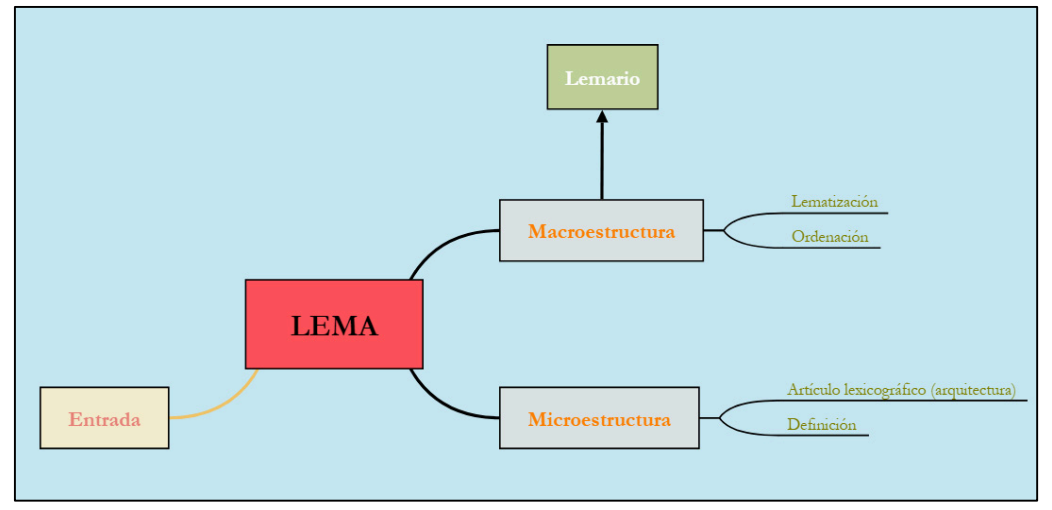

\section{CONCLUSIONES}

A lo largo de este estudio se ha presentado una selección y estructuración de los datos lexicográficos para la microestructura de un diccionario de especialidad muy concreto: una herramienta de consulta lexicográfica que recoge la terminología propia del estudio y la elaboración de diccionarios y cumple funciones comunicativas y comunicativas. Estos datos han sido dispuestos y organizados según estas funciones; por tanto, son datos lexicográficos de naturaleza comunicativa: categoría gramatical, ortografía y variantes gráficas, pronunciación, sinónimos y ejemplos, y datos lexicográficos de naturaleza cognitiva: clasificación temática, definición lexicográfica, información especializada y red temática.

En este sentido, se han alcanzado los objetivos planteados al inicio de la investigación: el diseño de la microestructura del Diccionario de terminología lexicográfica del español, si bien aún quedan muchos aspectos por determinar, por ejemplo, el diseño de la macroestructura (fuentes, corpus y criterios de selección), el diseño de la interfaz lexicográfica definitiva, o la creación del sistema de remisiones internas (medioestructura), entre otros, los cuales serán necesariamente atendidos en investigaciones futuras. 


\section{REFERENCIAS BIBLIOGRÁFICAS}

Agerbo, H. (2018). "Explaining meaning in lexicographical information tools". En P. A. Fuertes-Olivera (Ed.), The Routledge Handbook of Lexicography. Londres, Nueva York: Routledge, pp. 58-77.

Ahumada Lara, I. (2006) (dir./ed.). Diccionario Bibliográfico de la Metalexicografia del Español. (OrígenesAño 2000). Jaén: Servicio de Publicaciones de la Universidad de Jaén.

Ahumada Lara, I. (2009) (dir./ed.). Diccionario Bibliográfico de la Metalexicografia del Español. (2001-2005). Jaén: Servicio de Publicaciones de la Universidad de Jaén.

Ahumada Lara, I. (2014) (dir./ed.). Diccionario Bibliográfico de la Metalexicografía del Español. (2006- 2010). Jaén: Servicio de Publicaciones de la Universidad de Jaén.

Atkins, B. T. S. (2008). "Theorical Lexicography and its Relation to Dictionary-making”. En T. Fontenelle (ed.), Practical lexicography. A reader. Nueva York: Oxford University Press, pp. 31-50.

Bergenholtz, H. (2015). "Historia y actualidad de los Diccionarios en línea de Danés", Estudios de Lexicografia, 4, pp. 43-70.

Bergenholtz, H. y Tarp, S. (eds.) (1995). Manual of Specialised Lexicography. Amsterdam, Philadephia: John Benjamins.

Bosque Muñoz, I. (1982). "Sobre la teoría de la definición lexicográfica", Verba: Anuario galego de filoloxia, 9, pp. 105-124.

Camacho Niño, J. (2009). "Terminología lexicográfica en diccionarios generales del español (S. XIX)", Res Diachronicae, 7, pp. 53-63.

Camacho Niño, J. (2014). Teoría de la lexicografía en diccionarios monolingües del español (Orígenes-Siglo XXI). (Tesis doctoral inédita). Departamento de Filología Española. Universidad de Jaén.

Camacho Niño, J. (2015). "La terminología lexicográfica en los diccionarios generales del español: propuesta de un diccionario de especialidad", Estudios de Lexicografía, 7, pp. 79-114.

Camacho Niño, J. (2016a). "Terminología lexicográfica en la 23a edición del DRAE (2014). Estudio y tratamiento lexicográfico", Études Romanes de Brno, 37/2, pp. 203-227.

Camacho Niño, J. (2016b). "Un capítulo poco conocido del estudio diccionarístico: La terminografía lexicográfica. Estado y propuestas”, Revista de lexicografia, 22, pp. 93-121.

Camacho Niño, J. (2019). "Situaciones, necesidades y usuarios. Aproximación a las funciones del diccionario de especialidad lexicográfica", La investigación en lexicografía hoy: diccionarios bilingües, lingüistica y uso del diccionario. Anejos de la revista Quaderns de Filologia. Estudis Lingüistics, pp. 221-236.

Contreras Izquierdo, N. M. (2008). El diccionario de lengua y el conocimiento en la sociedad actual. Jaén: Servicio de Publicaciones de la Universidad de Jaén.

Fuertes-Olivera, P. A. (2012). "La lexicografía de internet: el Diccionario inglés-español de contabilidad", Círculo de Lingüistica de la Comunicación, 52, pp. 21-56.

Fuertes-Olivera, P. A. y Tarp, S. (2008). "La Teoría Funcional de la Lexicografía y sus consecuencias para los diccionarios de economía del español”, Revista de Lexicografía, XVI, pp. 75-95.

Fuertes-Olivera, P. A. y Tarp, S. (2014). Theory and Practice of Specialised Dictionaries. Lexicography versus Terminography. Berlín, Boston: De Gruyter Mouton.

Garriga Escribano, C. (2003). "La microestructura del diccionario: las informaciones gramaticales". En A. M. ${ }^{a}$ Medina Guerra (coord.), Lexicografía española. Barcelona: Ariel, pp. 103-126.

Gouws, R. H. (2018). "Dictionaries and access". En P. A. Fuertes-Olivera (ed.), The Routledge Handbook of Lexicography. Londres, Nueva York: Routledge, pp. 43-58.

Hartmann, R. K. K. y James, G. (2001). Dictionary of Lexicography. Londres, Nueva York: Routledge.

Haensch, G. y Omeñaca, C. (2004). Los diccionarios del español en el siglo XXI. Salamanca: Ediciones Universidad de Salamanca. 
Jacinto García, E. (2015). Forma y función del diccionario. Hacia una teoría general del ejemplo lexicográfico. Jaén: Servicio de Publicaciones de la Universidad de Jaén.

Lara Ramos, L. F. (1992). "El discurso en el diccionario". En G. Wotjak (ed.), Estudios de lexicografía y metalexicografía del español actual. Tübingen: Max Niemeyer, pp. 1-12.

Martínez de Sousa, J. (1995). Diccionario de lexicografia práctica. Barcelona: Bibliograf.

Medina Guerra, A. M. ${ }^{a}$ (2003). "La microestructura del diccionario: la definición". En A. M. ${ }^{a}$ Medina Guerra (coord.) Lexicografía española. Barcelona: Ariel, pp. 127-146.

Porto Dapena, J. Á. (2002). Manual de técnica lexicográfica. Madrid: Arco Libros.

Porto Dapena, J. Á. (2014). La definición lexicográfica. Madrid: Arco Libros.

Tarp, S. (2008). Lexicography in the Borderland between Knowledge and Non-Knowledge. General Lexicographical Theory with Particular Focus on Learner's Lexicography. Tübingen: Max Niemeyer Verlag.

Tarp, S. (2013). "Lexicographical functions". En R. H. Gouws, U. Reid, W. Schweickard y H. E. Wiegand (eds.), Dictionaries. An International Encyclopedia of Lexicography. Supplementary Volume: Recent Developments with Focus on Electronic and Computational Lexicography. Berlín, Boston: De Gruyter Mouton, pp. 460-468.

Tarp, S. (2015). "La teoría funcional en pocas palabras", Estudios de Lexicografía, 4, pp. 31-42.

Wiegand, H. E. (2013). "Microstructure in printed dictionaries". En R. H. Gouws, U. Reid, W. Schweickard y H. E. Wiegand (Eds.), Dictionaries. An International Encyclopedia of Lexicography. Supplementary Volume: Recent Developments with Focus on Electronic and Computational Lexicography. Berlín, Boston: De Gruyter Mouton, pp. 149-214.

Wiegand, H. E., Beißwenger, M., Gouws, R. H., Kammerer, M., Storrer, A. y Wolski, W. (Eds.) (2010, 2017). Wörterbuch zur Lexikographie und Wörterbuchforschung. Dictionary of Lexicography and Dictionary Research. Berlín, Boston: De Gruyter Mouton. 